\title{
PHYLOGENETIC DIVERSITY OF PLANT METACOMMUNITY OF THE DNIEPER RIVER ARENA TERRACE WITHIN THE 'DNIEPER-ORILSKIY' NATURE RESERVE
}

\author{
OLEXANDER ZHUKOV ${ }^{1}$, OLGA KUNAH ${ }^{1}$, YULIA DUBININA², DMITRY GANGA³, \\ GALINA ZADOROZHNAYA ${ }^{4}$
}

${ }^{1}$ Department of Zoology and Ecology, Oles Honchar Dnipro National University, pr. Gagarina, 72, 49010 Dnipro, Ukraine; e-mail:zhukov_dnipro@ukr.net

${ }^{2}$ Department of Ecology and Information Technologies, Melitopol Institute of Ecology and Social Technologies of the Open International University of Human Development 'Ukraine', Interculturnaya St., 380, 72316 Melitopol, Ukraine; e-mail: dubinina4884@ya.ru

4'Dnieper-Orilskiy' Nature Reserve, 52030 Obukhovka, Dniprovsk district, Dnipropetrovsk region, Ukraine

${ }^{5}$ Department of Human and Animal Physiology, Oles Honchar Dnipro National University, pr. Gagarina, 72, 49010

Dnipro, Ukraine; e-mail:vinograd03@i.ua

Abstract

Zhukov O., Kunah O., Dubinina Y., Ganga D., Zadorozhnaya G.: Phylogenetic diversity of plant metacommunity of the Dnieper river arena terrace within the 'Dnieper-Orilskiy' Nature Reserve. Ekológia (Bratislava), Vol. 36, No. 4, p. 352-365, 2017.

This article presents the features of the phylogenetic organization of the plant communities of the Dnieper River terrace within the 'Dnieper-Orilskiy' Nature Reserve and the patterns of its spatial variation involving remote sensing data of the Earth's surface. The research materials were collected in the period 2012-2016 from within the nature reserve. The research polygon is within the first terrace (arena) of the Dnieper valley. Sandy steppe, meadow, forest and marsh communities within the Protoch river floodplain and the Orlova ravine, as well as artificial pine plantations were the habitats present within the research polygon. The vegetation description was carried out on $10 \times 10 \mathrm{~m}\left(100 \mathrm{~m}^{2}\right)$ plots. A total of 94 geobotanical descriptions were made. Data on plant phylogeny was obtained by the Phylomatic service. Phylogenetic diversity of the communities was assessed by the Faith, Simpson and Shannon indices. Phylogenetic analysis was performed by means of a double principal coordinate analysis (DPCoA). The vegetation cover within the investigated polygon was represented by 189 species. Abundance Phylogenetic Deviation (APD) for the investigated metacommunity was evaluated to -0.53 , which is statistically significantly different from random alternatives $(p=0.001)$. The APD negative value indicates that phylogenetic organization of the investigated metacommunity is overdispersed. The permutation procedure allowed us to establish that the eigenvalues of the DPCoA-axes obtained as a result of the real phylogenetic tree were significantly higher than their own number for the random phylogenetic trees for the first seven axes. This indicates that the first seven axes are useful for additional information on the ordination structure of the metacommunity.

Key words: phylogeny, ecophylogenetics, diversity, community ordination, randomization. 


\section{Introduction}

The study of the species composition of communities is a central problem of ecology (Pavoine et al., 2004). A community is defined as a set of species found in the same habitat (Pavoine et al., 2009). The species composition of a biotic community is the result of mutual action of evolutionary and ecological mechanisms (Ricklefs, 1987) and is subject to niche-dependent (Diamond, 1975; Tilman, 1982; Weiher, Keddy, 1999), neutral (Bell, 2001; Hubbell, 2001) and historical (Ricklefs, 1987; Ricklefs, Schluter, 1993) processes. It is believed that information about the phylogeny can help answer questions about the relative role of ecological niche, neutral and historical processes of a community and certain mechanisms of formation of community structures (Cavender-Bares et al., 2009).

Many different ordination techniques are available for the analysis of the community structure (Hill, 1973; Doledec et al., 1996; Legendre, Gallaghe, 2001; Zhukov, 2015a, b; Sokolov, Zhukov, 2016). An important task is to include the information on the ecological properties of species in the ordination procedure. An effective tool for analysing the properties of plant communities is ecomorphic analysis according to O. L. Belgard (Belgard, 1950, 1971; Potapenko et al., 2016; Zhukov, Potapenko, 2017; Zhukov et al., 2016). This approach can be used to assess the relationship of similarity and differences between members of a community. Phytoindication assessment is also effective for the detection of differences both between species and between communities (Zhukov et al., 2016). But a significant amount of environmentally relevant information is contained in the data on the phylogeny of the species that make up the community. Pairwise species' phylogenetic distances measure the divergence times during the evolutionary history and are often argued to be a good synthetic measure of species' ecological differentiation (Faith, 1992; Webb, 2000; Mouquet et al., 2012; Chalmandrier et al., 2013). Phylogeny is the bearer of indirect information about the common origin, common adaptation and potential competition between species (Webb et al., 2002). Phylogenetically related species tend to be adapted to similar habitats as they are characterized by similar biological properties. This pattern is called 'ecological niche conservatism' (Lord et al., 1995). In this case, the local communities that are distributed along an environmental gradient may show a surplus of related species that coexist locally, which is an example of 'spatial phylogenetic clustering' (Hardy, 2008). Instead, the pattern of 'spatial phylogenetic overdispersion' (when sister species occur together less often than can be expected based on random conditions) may be the result of: 1) the exclusion by competition between two closely related species with similar ecological requirements; 2 ) mortality, which depends on the density of related species (Gilbert, Webb, 2007); 3) ecological speciation, which is caused by habitat differentiation between sister species (Cavender-Bares et al., 2004, 2006). Information about these processes can be obtained as a result of investigation of correlation between common occurrence and phylogenetic distance of pairs of species in natural communities. Such spatial phylogenetic structure can be biogeographical in origin, when the rate of speciation is faster than the rate of settlement of species across biogeographical barriers (Webb et al., 2002; Hardy, Senterre, 2007). An important issue is to establish whether there are numerous species randomly distributed within the 
phylogenetic structure? This pattern can be quantitatively measured by the index of phylogenetic deviation in abundance (Abundance Phylogenetic Deviation - APD) (Hardy, 2008). On the phylogenetic clustering of species abundance, the index APD $>0$ when numerous species are only typical for certain phylogenetic clades. If APD $<0$, this designates phylogenetic overdispersion, that is, a situation where the most numerous species are distributed in phylogenetically different clades (Hardy, 2008).

Information about community can be represented by two matrices: the first matrix contains distances or differences between species, and the second contains information about abundance (or presence/absence) of species (rows) in the community (columns). Differences between species can be assessed by their taxonomy (Izsáki, Papp, 1995; Warwick, Clarke, 1995), morphology (Blondel et al., 1984; Cody, Mooney, 1978; Losos, 1992), or traits (Lamouroux et al., 2002). Indices of species diversity are usually calculated on the basis of relationships between the number of species and the number of individuals of any selected species in the community. The most common diversity indices are the Gini-Simpson (Simpson, 1949) and Shannon (Shannon, 1948) indices. However, these indices do not account for differences between species. 'The indices based on the features' indicate a number of indices that include differences among species based on one or more biological properties (Pavoine et al., 2004). The main objective of the double principal coordinate analysis (DPCoA) is to assess the community typology based on specific information about the heterogeneity of identities and differences between the species and relative abundance of species (Pavoine et al., 2004).

The phylogeny of the plants at the species level was generated using the data on gene sequence from species included in the GenBank (http://www.ncbi.nlm.nih.gov/genbank) for terrestrial plants (Zanne et al., 2014). This phylogeny contains data on 31,749 species of plants and is based on seven gene regions (18S rDNA, 26S rDNA, ITS, matK, $\mathrm{rbcL}$, atpB and trnL-F), which include both gradually evolving regions and more rapidly evolving regions (Qian, Jin, 2016). The maximum-likelihood estimates in the phylogeny were time-scaled based on 39 fossil calibrations. The phylogeny includes $98.6 \%$ of families of extant seed plants represented in the world flora, about 11\% of species (Qian et al., 2014 ) and $51.6 \%$ of genera (Zanne et al., 2014). The nomenclature of orders and families is in accordance with the APG III (2009). Thus, the data presented in this phylogeny can be used for the reconstruction of the phylogeny in ecological and biogeographic studies of seed plants (Qian, Jin, 2016). Phylogenetic structure is particularly informative in addressing the role of neutral processes in organization of groupings. In a neutral community, no ecological process regarding species-species or species-environment interactions can generate a phylogenetic structure in the spatial distribution of species (Hardy, 2008). However, purely neutral processes can create complex structures in the spatial distribution of species (Ulrich, 2004), so that testing for a spatial phylogenetic structure by randomizing a data set, for example, permuting species abundances among locations may not be adequate (Gotelli, 2000).

The aim of this paper is to determine the importance of the phylogenetic components in the organization of plant metacommunity of the Dnieper arena within the 'DnieperOrilskiy' Nature Reserve. 


\section{Material and methods}

The materials were collected in the period 2012-2016 within the 'Dnieper-Orilskiy' Nature Reserve. The investigated polygon is within the first above-floodplain terrace (arena) of the Dnieper. Habitats within this area are represented by sandy steppe, grassland, forest and wetland communities in the floodplain of the r. Protoch and the Orlova ravine, and pine plantations' descriptions of vegetation were carried out using standard geobotanical techniques (Voronon, 1973) for $10 \times 10 \mathrm{~m}\left(100 \mathrm{~m}^{2}\right)$ plots. 94 geobotanical sample descriptions were made. Projective plant cover was assessed visually. Plants were identified using 'The Identification Key to Higher Plants in Ukraine' (Dobrochaeva, Kotov, 1987). Plant names were given according to the data base The Plant List (2013); the taxonomy was given according to the database Euro + Med (2016). Information about the plants' phylogeny was obtained using the service Phylomatic (Webb, Donoghue, 2005). The phylogeny was based on the information about the gene sequences contained in GenBank (http://www.ncbi.nlm.nih.gov/genbank) for terrestrial plants (Zanne et al., 2014). Information about the phylogeny was applied to assess the phylogenic aspect of the diversity of plant communities. One of the indices proposed to measure the diversity within a community by regrouping individuals into categories (usually species) and considering their abundances and number was the Havrda \& Charvat index (Havrda, Charvat, 1967):

$$
H_{a}(p)=\left(1-\sum_{i=1}^{n} p_{i}^{a}\right)(a-1),
$$

where $p=\left(p_{1}, \ldots p_{i}, \ldots p_{n}\right), p_{i}$ is the relative abundance of the $i$ th category in a community of $n$ categories, and $a$ is a scaling constant $(\mathrm{a} \geq 0)$ that weights the importance of rarity (Pavoine et al., 2009). If $a$ is equal to zero, $H_{a}$ reduces to the number of categories minus 1 (hereafter referred to as richness). Hence, with this diversity index, the categories that had low abundances in the community are given weights equal to the categories with high abundances. As $a$ increases, the weights of the rarest categories in the community decrease. When $a$ tends to 1 , then $H_{a}$ tends to the Shannon (1948) index. When $a=2$, then $H_{a}$ is equal to the Simpson (1949) index (Pavoine et al., 2009; Sokolov, Zhukov, 2016).

The phylogeny must be ultrametric in order to partition a phylogeny along a hierarchy such that all tips are at equal distance from the root node and we must divide the phylogeny into periods of evolutionary time from the root node to the tips of the tree. The periods are numbered from the tips to the root. Let $\left(t_{1}, t_{2}, \ldots, t_{N}\right)\left(0 \leq t_{1} \leq t_{2} \leq \ldots \leq t_{N}\right)$ be the end time of the evolutionary periods $\left(t_{0}=0\right)$. Pavoine et al. (2009) proposed an index of phylogeny diversity (PD) that can be adjusted for rarity $\left(I_{a}\right)$ as:

$$
I_{i}=\sum_{K=1}^{N}\left(t_{K}-t_{K-1}\right) H_{a, K},
$$

where $H_{a^{\prime} K}$ is the diversity index $H_{a}$ applied to the Kth period. With $a=0, H_{0}$ is the richness and $I_{0}$ is Faith's (1992) PD index minus the height of the tree. When $a$ tends to $1, I$ is thus a generalization of the Shannon index $\left(H_{1}\right)$ to account for evolutionary history. With $a=2, \mathrm{H}_{2}$ is the Simpson index and $I_{2}$ is Rao's quadratic entropy (QE) applied to phylogenetic distances between species (Rao, 1982; Pavoine et al., 2009).

To the analysis of $I_{a}$ within a community, the analysis of $I_{a}$ within and between subcommunities can be added. Subcommunities can be defined in space (e.g., local subcommunities in a region) or through time (e.g., a subcommunity corresponds to the state of a focal community at a given time period) and the mixing of proportions allow one to choose how to weight subcommunities. In our study, we considered the plants subcommunities in geographical space. The partitioning of $I_{a}$ over evolutionary periods could then be applied to the averaged community ( $\gamma$-component of the diversity), to the subcommunities ( $\alpha$-component of the diversity), and to the phylogenic diversity between the subcommunities $(\beta=\gamma-\alpha)$ (Pavoine et al., 2009).

A permutation test was applied to determine which periods of the phylogeny were affected by differences between subcommunities. The tips of the whole phylogenetic tree were randomized so that the connection between species abundance and the phylogenetic tree was permuted (Hardy, 2008). For each permutation at each evolutionary period $\mathrm{K},(\beta / \gamma)_{\mathrm{K}}$ was calculated as a statistic of phylogenetic differentiations among the subcommunities (Hardy, Senterre 2007; Pavoine et al., 2009). A higher value of $(\beta / \gamma)_{\mathrm{K}}$ than expected from the species pool indicated phylogenetic clustering (high $\beta$, low $\alpha$ ) at period $\mathrm{K}$, which meant that the subcommunities had fewer lineages that originated in period $\mathrm{K}$ than expected and/or only one or a few of these lineages dominate in abundance. On the contrary, a lower value of $(\beta / \gamma)_{\mathrm{K}}$ indicated phylogenetic overdispersion (low $\beta$, high $\beta$ ) at period $\mathrm{K}$, which meant that the subcommunities had more lineages that originated in period $\mathrm{K}$ than expected and/or the abundance of these 
lineages is even. Accordingly, a $p$-value was associated to any period $\mathrm{K}$ as the number of permutations of the tips where $(\beta / \gamma)_{\mathrm{K}}$ was higher (for phylogenetic clustering) or alternatively lower (if phylogenetic overdispersion is tested) than the observed $(\beta / \gamma)_{\mathrm{K}}$ value (Pavoine et al., 2009).

Phylogenetic analysis by means of Double Principal Coordinate Analysis (DPCoA) (Pavoine et al., 2004) was conducted using library ade 4 (Dray et al, 2007) in the environment $\mathrm{R}$ ( $\mathrm{R}$ Core Team, 2016). The procedure of analysis and additional scripts are described in the work of Pavoine et al., 2009. For each random permutation of the phylogenetic tree, as mentioned above, we calculated the eigenvalues of the DPCoA-axes and with the function rand test from the library ade4, the Monte-Carlo test was performed. Statistical difference from the random alternative for each DPCoA-axis was assessed. This approach let us understand the degree in which phylogenetic information increases the quality of the ordination in comparison with the phylogenetic random alternative. Statistical analysis was conducted in Statistica 10.0.

\section{Results}

The vegetation was found to be represented by 189 species within the research polygon. The division Bryophyta was represented by Syntrichia ruralis, and the division Pinophyta was represented by Pinus sylvestris. Moss species' diversity in the Dnieper terrace within the 'Dnieper-Orilskiy' Nature Reserve is much higher, but requires a separate study. Mosses with

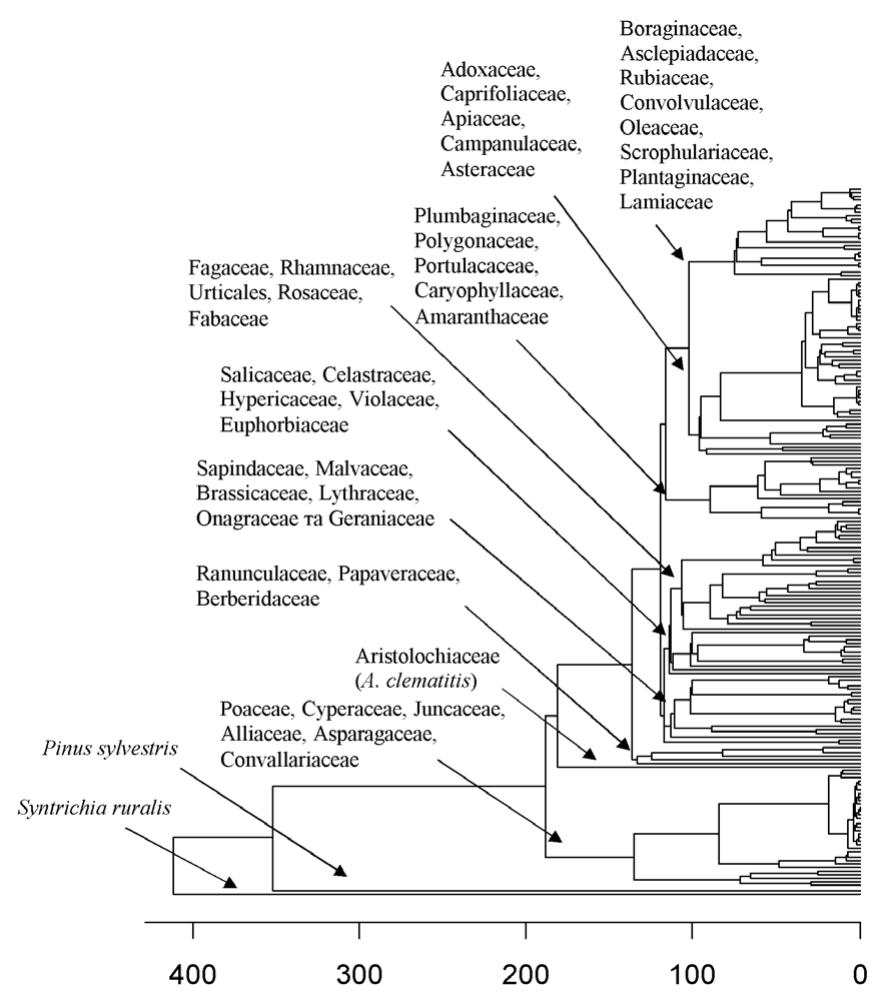

Fig. 1. Phylogeny of the vegetation of the Dnieper arena. The horizontal axis presents time of divergence in million years. lichens Cladonia foliacea (Huds.) Willd. and Cornicularia steppae Savicz form cushions (Kosets, Tkachenko, 1973). Pine plantations within the study area form artificial forest stands, though pines are also present at sites of past fires, where in some cases of natural recovery of this tree has occurred. Overall, the angiosperms in the study area are represented by187 species.

The phylogeny of the plants that make up the vegetation of the study area is shown in Figure 1. The orders Poales and Asparagales diverged on the phylogenetic trees about 180 million years ago. According to others, Asparagales appeared 120 million, and 
$\mathrm{T}$ a b l e 1. The eigenvalues of DPCoA-axes for observed data and phylogenetic matrix, as well as eigenvalues for randomized phylogenetic matrices (99 permutations) and evaluation of the significance $p$-level.

\begin{tabular}{|l|c|c|c|c|c|}
\hline \multirow{2}{*}{ Axes } & \multirow{2}{*}{ Eigenvalues } & \multicolumn{2}{|c|}{ Eigenvalues for randomized phylogenetic matrices } & \multirow{2}{*}{ p-level } \\
\cline { 2 - 5 } & & Mean \pm st. error & Minimum & Maximum & \\
\hline 1 & 12.90 & $4.07 \pm 0.150$ & 2.44 & 11.32 & 0.01 \\
\hline 2 & 2.90 & $1.86 \pm 0.050$ & 1.09 & 3.17 & 0.05 \\
\hline 3 & 1.90 & $1.18 \pm 0.023$ & 0.80 & 2.09 & 0.02 \\
\hline 4 & 1.43 & $0.87 \pm 0.015$ & 0.54 & 1.30 & 0.01 \\
\hline 5 & 0.99 & $0.63 \pm 0.011$ & 0.41 & 0.94 & 0.01 \\
\hline 6 & 0.69 & $0.49 \pm 0.010$ & 0.23 & 0.78 & 0.02 \\
\hline 7 & 0.62 & $0.36 \pm 0.008$ & 0.18 & 0.58 & 0.01 \\
\hline 8 & 0.17 & $0.28 \pm 0.006$ & 0.16 & 0.46 & 0.98 \\
\hline 9 & 0.12 & $0.21 \pm 0.005$ & 0.11 & 0.37 & 0.97 \\
\hline 10 & 0.08 & $0.16 \pm 0.004$ & 0.08 & 0.28 & 1.00 \\
\hline
\end{tabular}

Poales - 118 million years ago (Hertweck et al., 2015). Within the study area, Asparagales is represented by 2 families, 4 genera and 5 species, and Poales is represented by 3 families, 18 genera and 27 species.

Within the studied polygon, the order Piperales includes only one species Aristolochia clematitis. Phylogenetically related to this order are the orders Sapindales, Malvales, Brassicales, Myrtales and Geraniales, which form the Eurosids II group. This group appeared on the phylogenetic tree 110 million years ago. The order Sapindales is represented by one family and one genus with 4 species. The order Malvales is represented by one family with two genera and two species. The order Brassicales is represented by one family, 6 genera and 7 species. The order Myrtales is represented by the families Lythraceae (1 genus, 1 species) and Onagraceae ( 2 genera, 2 species). The order Geraniales is represented by 1 family, 1 genus and one species. The age of the orders Malpighiales and Celastrales is 100-110 million years. Within the research polygon the order Malpighiales is represented by the families Salicaceae, Hypericaceae, Violaceae, Euphorbiaceae, which comprise 5 genera and 10 species. The order Celastrales is represented by one species Euonymus europaeus.

The group Eurosids I is represented by the orders Fagales, Fabales and Rosales. Their age is estimated at 117-108 million years (Wikström et al., 2001). The order Fagales is represented by one species, Quercus robur. The order Rosales is represented by the families Rhamnaceae, Urticales, Rosaceae, Ulmaceae, Moraceae, and Cannabaceae, which within the research polygon include 16 species in 13 genera. The order Fabales is represented by only the family, Fabaceae, with 13 species and 13 genera.

The group Core Eudicots includes the order Caryophyllales. Its age is $90-83$ million years (Wikström et al., 2001). The order Caryophyllales is represented by the families Plumbaginaceae, Polygonaceae, Portulacaceae, Amaranthaceae and Caryophyllaceae, which consists of 12 genera represented by 17 species.

The group Asterids II is represented by the orders Dipsacales, Apiales and Asterales. The age of this group is about 95 million years. Within the research polygon, the order Dipsacales is represented by the families Adoxaceae (only one species Sambucus nigra) and Caprifoli- 
aceae (two genera and two species). The order Apiales is represented by the family Apiaceae (6 genera, 6 species). The order Asterales is represented by the families Campanulaceae (only one species Campanula patula) and Asteraceae (24 genera, 37 species).

The group Asterids I is represented by the orders Boraginales, Gentianales, Lamiales, and Solanales. The age of this group is about 75 million years. The order Boraginales is represented by the family Boraginaceae ( 2 genera, 2 species). The order Gentianales is represented by the families Apocynaceae (2 genera, 2 species) and Rubiaceae (1 genera, 3 species). The order Solanales is represented by the family Convolvulaceae ( 2 genera, 2 species). The order Lamiales is represented by the families Oleaceae (one species Fraxinus excelsior), Scrophulariaceae (2 genera, 3 species), Lamiaceae (7 genera, 7 species) and Plantaginaceae (2 genus, 4 species).

The Abundance Phylogenetic Deviation index (APD) for the investigated metacommunity takes the value 0.53 , which statistically significantly differs from the random alternatives $(p=0.001)$. An APD negative value indicates overdispersion in the phylogenetic organization of the metacommunity.

Community ordination using the DPCoA procedures has allowed us to establish that the first 4 axes are characterized by their eigenvalues which are greater than 1 (Table 1). We conducted a permutation procedure in which we generated a random phylogenetic structure using random replacement of the species on the tips of the phylogenetic branches. It is established that the eigenvalues of axes calculated for DPCoA procedures with the real phylogenetic tree significantly exceed their eigenvalues of axes for random phylogenetic trees for the first seven axes. This indicates that the first seven axes are useful for additional ordination information about the structure of the metacommunity.

DPCoA axis 1 was found to reflect variation in metacommunity representatives of the order Poales. The positive value of this axis indicates grassland communities (steppe, meadow and bog), which are dominated by grasses, bromeliads, and sedges. The negative axis corresponds to the forest communities, where the importance of this taxonomic group is considerably less.

DPCoA axis 2 reflects the opposite dynamic of the role in communities of representatives of the order Asterales, on the one side, and Poales, on the other. Areas with relative predominance of Asterales over Poales form diffuse patches of plant cover with complex spatial configuration. The most positive value for axis 2 was characteristic for grasslands and marsh communities, but for the centre of the polygon within the sand steppe zone, there was also relative predominance of Asterales over Poales.

DPCoA axis 3 showed a tendency of synchronous changes of the role in the community of the orders Asterales and Poales, on the one side, and the opposite dynamic of the plants of the order Malpighiales. The order Malpighiales within the polygon is represented mainly by forest species (Populus, Salix) or forest herbs (Viola, Hypericum), which explains the fact that this axis is able to differentiate areas with broadleaved forests from other types of vegetative cover.

DPCoA axis 4 reflects synchronous changes in the values in the grouping of the orders Poales, Malpighiales and Sapindales as opposed to the role of the grouping mosses Fabales, Pinus sylvestris, Chelidonium majus and Berberis vulgaris. Spatial variation of this axis points to restricted areas with positive values denoting increase in the grouping Fabales and some 
other species. DPCoA axis 5 is sensitive to the opposite dynamics of variation in values in the grouping of representatives of the order Sapindales, on the one hand, and Malpighiales and Fabales, on the other. DPCoA axis 5 takes positive values in the area of significant anthropogenic transformation due to fires and erosion of sandy soil. Negative values of the axis correspond to stable vegetation plots, in which Acer tataricum is represented. DPCoA axis 6 reflects synchronous dynamic of variation in the values in the grouping of representatives of the orders Sapindales and Malpighiales. DPCoA axis 7 is associated with simultaneous variation in the values in the grouping of plants of the family Cyperaceae and some Ranunculales, on the one hand, and the orders Sapindales and Fabales, on the other.

The total phylogenetic diversity and its fractions are presented in Table 2. The partitions of $I_{0}$, $I_{1}, I_{2}$ between phylogenetic periods is represented in Figure 2. By definition, the number of phylogenetic lines decreases from the phylogenetic tree tips to its roots. Consequently, the environmental contribution of the periods decreases from the tips to the root in the case of $I_{0}$ and less in the case of $I_{1}, I_{2}$.

T a b l e 2. Overall value of $I_{a}$ (total number for all phylogenetic periods, $a=0,1,2$ ) and its share within and between sites (\% indicates the proportion of the total diversity that corresponds to the components of diversity within or between sites).

\begin{tabular}{|l|c|c|c|c|c|c|}
\hline Diversity components & \multicolumn{2}{|c|}{$I_{0}$} & \multicolumn{2}{c|}{$I_{1}$} & \multicolumn{2}{c|}{$I_{2}$} \\
\hline Between-site diversity & 2285.98 & $29.44 \%$ & 575.69 & $77.31 \%$ & 193.86 & $89.70 \%$ \\
\hline Within-site diversity & 5478.66 & $70.56 \%$ & 168.92 & $22.69 \%$ & 22.26 & $10.30 \%$ \\
\hline Total diversity & 7764.64 & $100.00 \%$ & 744.60 & $100.00 \%$ & 216.12 & $100.00 \%$ \\
\hline
\end{tabular}

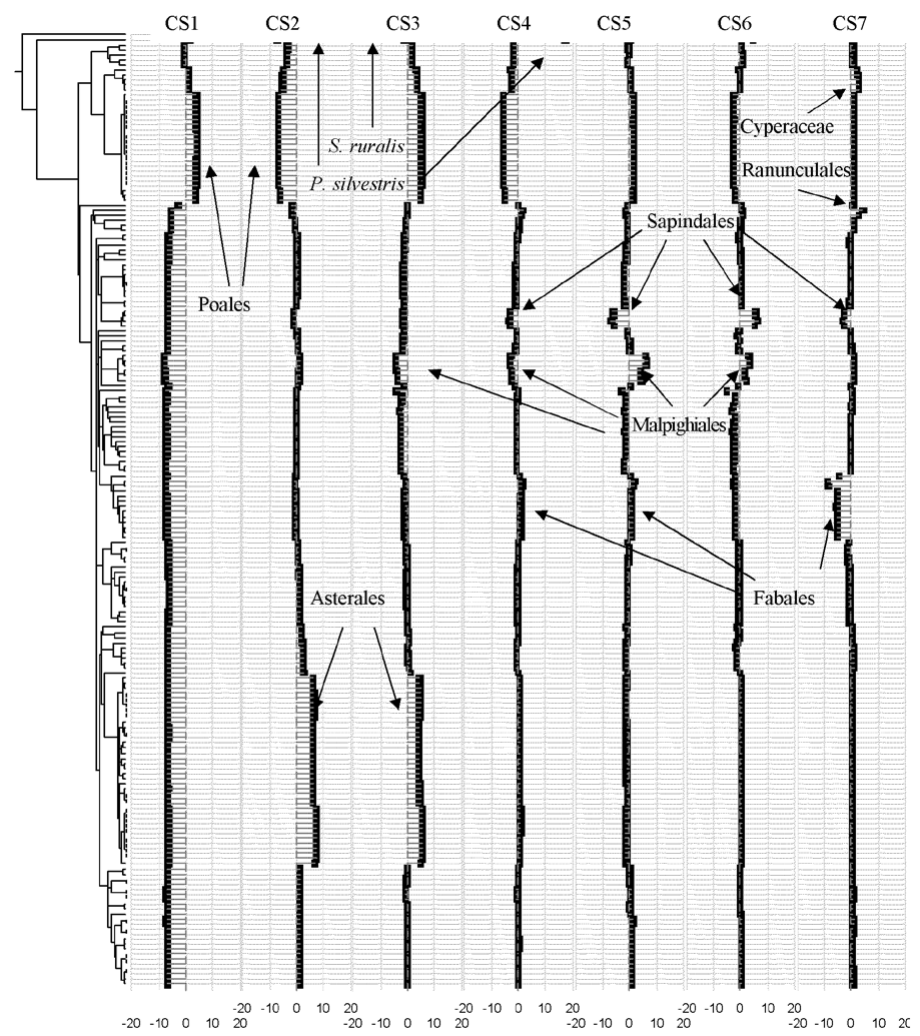

Fig. 2. The results of the DPCoA. On the left is the phylogenetic structure of the metacommunity. CS1-CS7 are weightings of species on the appropriate axis. 

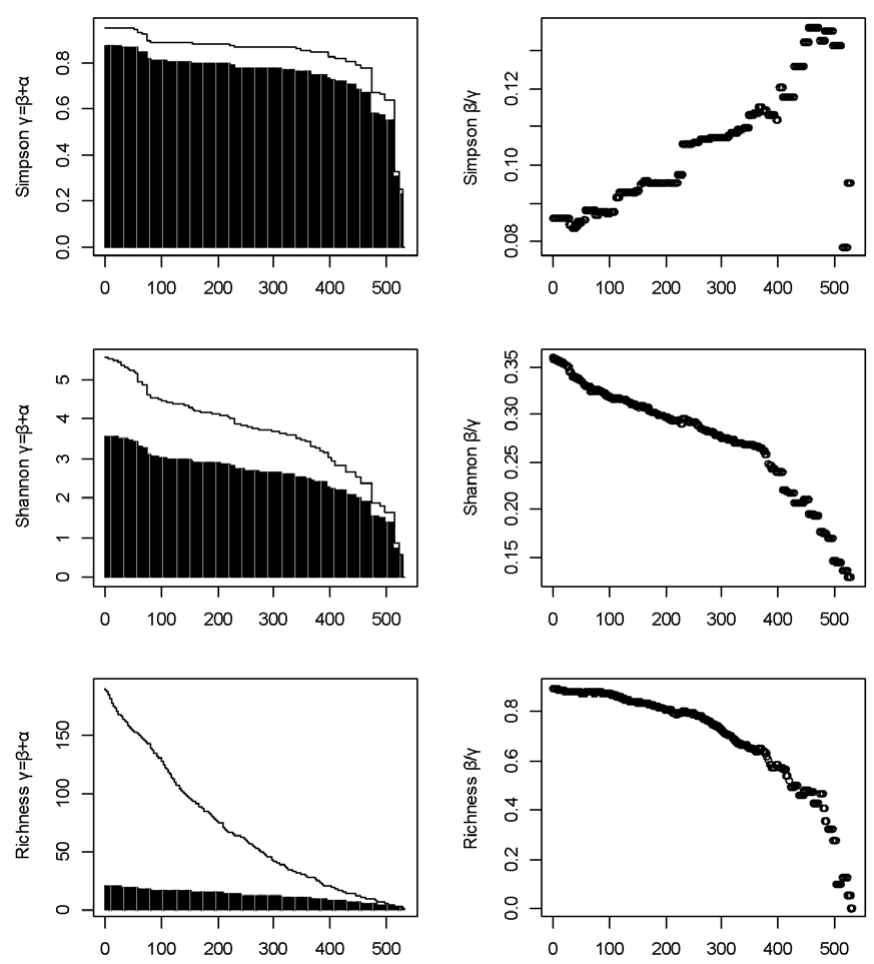

Fig. 3. Hierarchical partition of phylogenetic diversity along phylogenetic periods. Periods ranked from tips to the roots. A - the partition of the Simpson index $\alpha$-(black) and $\beta$-components (white region) along evolutionary time (the height of the black and white areas corresponds to $\gamma$-component); $\mathrm{B}$ and $\mathrm{C}$ are equivalent to the Shannon index (B) and the species richness $(\mathrm{C})$; D - the differences between sites (measured as the ratio of $\beta / \gamma$ Simpson indexes) in terms of evolutionary periods; $\mathrm{E}$ and $\mathrm{F}$ are equivalent to Shannon index (E) and species richness $(\mathrm{F})$. ruralis, Pinus sylvestris, Aristolochia clematitis, Chelidonium majus, Berberis vulgaris) and taxa such as Asparagales, Poales and Ranunculaceae. Other taxa form a homogeneous group of the level of aggregation of orders. A manifestation of homogeneity is the compactness of the respective spheroids in the space of the axes 1-4. In the space of the axes 5-8, the corresponding grouping of taxa exhibit their heterogeneity, which is reflected in the considerable proportion of the space that is covered by the relevant ellipsoids.

\section{Discussion}

Community formation patterns are determined by two main processes: filtering species that are able to demonstrate their strength in the community based on their tolerance to 
environmental conditions (Weiher, Keddy, 1995; Weiher et al., 1998) and competitive relationships among species, limiting the long-term co-existence of ecologically similar species (Gause, 1934; Elton, 1946; MacArthur, Levins, 1967; Chesson, 1991; Leibold, 1998). Based on the review of these processes, one can make opposite predictions about the similarity of phenotypic and phylogenetic proximity of species that coexist (Tofts, Silvertown, 2000; Webb, 2000). Where related species have similar physiological limits, and demonstrate evolutionary conservatism of ecological niches, environmental filtration will lead to the co-existence of phylogenetically closely related species. This pattern is called 'phylogenetic clustering' (Tofts, Sil-

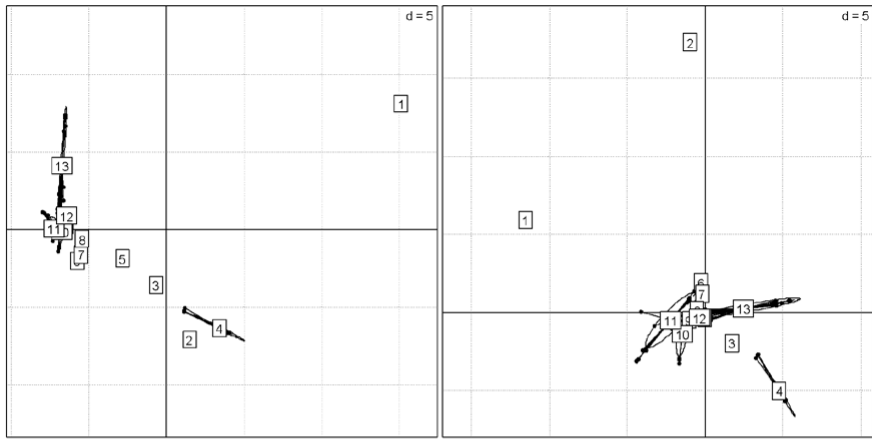

A

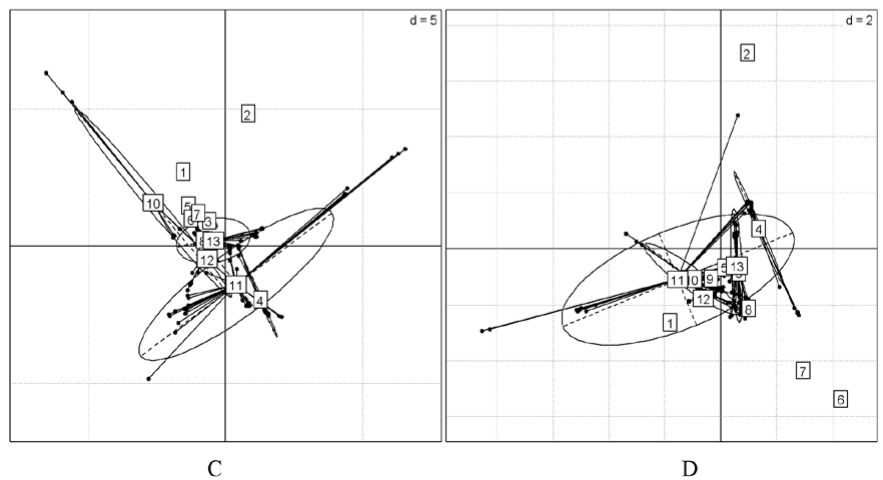

Fig. 4. Location of the monophyletic groups in the period, which corresponds to the beginning of intensive growth ratio $\beta / \gamma$ of Simpson index value in space of the axes obtained as a result of the DPCoA procedure (A - axis $1,2, \mathrm{~B}$ - axes 3 , 4, C - axes 5, 6; D - axes 7, 8).

Notes: 1 - Syntrichia ruralis; 2 - Pinus sylvestris; 3 - Asparagales; 4 - Poales; 5 - Aristolochia clematitis; 6 - Chelidonium majus; 7 - Berberis vulgaris; 8 - Ranunculaceae; 9 - Crassulaceae; 10 - Brassicaceae + Geraniaceae + Malvaceae + Myrtales + Sapindaceae; 11 - Celastraceae + Zygophyllaceae + Malpighiales + Fagaceae + Rosales + Fabales; 12 - Caryophyllales; 13 - Dipsacales + Apiaceae + Asterales + Gentianales + Boraginaceae + Lamiales. vertown, 2000; Webb, 2000; Cavender-Bares et al., 2004). Competitive exclusion should limit the coexistence of closely related species, if the species share common limiting resources, which leads to the opposite pattern - phylogenetic overdispersion (Cavender-Bares et al., 2004). The Abundance Phylogenetic Deviation Index for the researched metacommunity indicates the presence of phylogenetic overdispersion. The pattern of phylogenetic overdispersion may be the result of: 1) exclusion by competition between two closely related species with similar ecological requirements; 2) mortality, which depends on the density of related species (Gilbert, Webb, 2007); 3) ecological speciation, which is caused by habitat differentiation between sister species 
(Cavender-Bares et al., 2004, 2006). This feature of the organization of the metacommunity is most probably the result of intense competitive relationships in the fairly extreme conditions that prevail in the Dnieper terrace.

Double principal coordinate analysis (DPCoA) allows two matrices to be taken into account in community ordination procedure: the traditional matrix of distribution of species within habitats and the matrix that describes specific distance (Pavoine et al., 2004). Phylogenetic distance between species can be used in the analysis of the matrix, which allows one to assess the value of the phylogenetic track in the organization of the community. The eigenvalues of 1-7 axes, identified during the DPCoA procedure using phylogenetic matrix are statistically possibly different from random alternatives in an upward direction, which indicates additional information to explain the $\beta$-diversity that we obtained after considering the phylogenetic history of the species that composed the metacommunity investigated.

The connection of taxa with axes allows these axes to be interpreted. It should be noted that similar pairs of axes change the connection with certain taxa. Axis 1 and 2 (and to a lesser extent, 3 and 4 ) are associated with the order Poales, axes 2 and 3 are associated with the order Asterales, axes 3-6 are associated with the order Malpighiales, axes 4-7 are associated with the order Sapindales, axes 4, 5 and 7 are associated with the order Fabales. The vast majority of ordination techniques, including DPCoA, reveals only the linear component of real environmental trends, which are caused by the influence of ecological factors. In turn, the response of ecosystems to the impact of factors is usually nonlinear and is regulated by the familiar horseshoe dependency. Linear character has dependence when only a part of the functional range between factor and response is covered experimentally. The nonlinear nature of interconnections when using ordination techniques results in the so-called horseshoe effect, in consequence of which, one environmental factor in ordination reflection is marked by two or more axes. This fact explains why one taxon has a significant relationship with two or more consecutive axes. This situation is the result of the fact that ecological optima of the corresponding taxonomic groups are located within the studied polygon. Of course, the conception of optimum taxonomic groups is possible when there is ecological homogeneity of these groups. The qualitative and quantitative measure of homogeneity may be an ellipsoid configuration, which sets boundaries of the corresponding taxonomic groups in the space of the DPCoA-axes. For example, the ellipsoid of the order Poales in the space of the axes 1-2 and 3-4 (Fig. 4) is quite compact and well defined, although this order includes 27 species or $14.3 \%$ of the total species richness of the metacommunity. The same applies to the order Asparagales (38 species or $20.1 \%$ of total species richness) and some others.

It should be noted that an increase in the ordination number of axes is accompanied by an increase of the number of taxa that are associated with these axes and growth of the heterogeneity of projections of their ecological niches on the axis following a decrease in species richness of the taxa and a tendency towards a decrease in the level of these taxa. For example, axis 1 is largely related to one large taxon and the species Pinus sylvestris and Syntrichia ruralis. Axis 2 is largely related to two large taxa, axis 3 is largely related to three taxa, axes 4-6 are largely related to three or four taxa, axis 7 is largely related to four or five taxa; these taxa already have a rank lower than order. 


\section{Conclusion}

The phylogeny of plant species has proved to be an important component of the diversity of plant metacommunities. The current study found that the organization of the plant metacommunity of the Dnieper River terrace within the "Dnieper-Orilskiy" Nature Reserve is characterized by a phylogenetic pattern which may be estimated as overdispersion. The competitive relationship between the species in the community may be considered to be the most probable mechanism of the formation of overdispersion. An additional factor that should not be excluded is mortality, which depends on the density of related species and ecological speciation and leads to habitat differentiation between sister species. DPCoA procedure allowed us to establish that the greatest contribution to the $\beta$-diversity of the metacommunity is made by species of the orders (in decreasing order of importance of the contribution): Poales, Asterales, Malpighiales, Sapindales and Fabales.

\section{References}

Belgard, A.L. (1950). Forest vegetation of South-East part of the USSR (in Russian). Kiev: Kiev State University.

Belgard, A.L. (1971). Steppe forestry (in Russian). Moscow: Forest Industry.

Bell, G. (2001). Neutral macroecology. Science, 293, 2413-2418. DOI: 10.1126/science.293.5539.2413.

Blondel, J., Vuilleumier, F., Marcus, L.F. \& Terouanne E. (1984). Is there ecomorphological convergence among Mediterranean bird communities of Chile, California, and France. In M.K. Hecht, B. Wallace \& R.J. MacIntyre (Eds.), Evolutionary biology (pp. 141-213). New York: Plenum Press.

Cavender-Bares, J., Ackerly, D.D., Baum, D.A. \& Bazzaz F.A. (2004). Phylogenetic overdispersion in Floridian oak communities. Am. Nat., 163, 823-843. DOI: 10.1086/386375.

Cavender-Bares, J., Keen, A. \& Miles B. (2006). Phylogenetic structure of Floridianplant communities depends on taxonomic and spatial scale. Ecology, 87, S109-S122. DOI: 10.1890/00129658(2006)87[109:PSOFPC]2.0.CO;2.

Cavender-Bares, J., Kozak, K.H., Fine, P.V.A. \& Kembel S.W. (2009). The merging ofcommunity ecology and phylogenetic biology. Ecol. Lett., 12, 693-715. DOI: 10.1111/j.1461-0248.2009.01314.x.

Chalmandrier, L., Münkemüller, T., Gallien, L., de Bello, F., Mazel, F., Lavergne, S. \& Thuiller W. (2013). A family of null models to distinguish between environmental filtering and biotic interactions in functional diversity patterns. J. Veg. Sci., 24, 853-864. DOI: 10.1111/jvs.12031.

Chesson, P. (1991). A need for niches? Trends Ecol. Evol., 6, 26-28.

Cody, M.L. \& Mooney H.A. (1978). Convergence versus nonconvergence in Mediterranean-climate ecosystems. Annu. Rev. Ecol. Syst., 9, 265-321. https://doi.org/10.1146/annurev.es.09.110178.001405

Diamond, J.M. (1975). Assembly of species communities. In M.L. Cody \& J.M. Diamond (Eds.), Ecology and evolution of communities (pp. 342-444). Cambridge: Belknap Press of Harvard University Press.

Dobrochaeva, D.N. \& Kotov M.I. (1987). The identification key of higher plants in Ukraine (in Russian). Kiev: Naukova Dumka.

Doledec, S., Chessel, D., Ter Braak, C.J.F. \& Champely S. (1996). Matching species traits to environmental variables: a new three-table ordination method. Environ. Ecol. Stat., 3, 143-166. DOI: 10.1007/BF02427859.

Elton, Ch. (1946). Competition and the structure of ecological communities. J. Anim. Ecol., 15, 54-68. DOI: $10.2307 / 1625$.

Euro+Med (2006-2016). Euro+Med PlantBase - the information resource for Euro- Mediterranean plant diversity. Published on the Internet http://ww2.bgbm.org/EuroPlusMed/ [accessed 1st January 2016].

Faith, D.P. (1992). Conservation evaluation and phylogenetic diversity. Biol. Conserv., 61, 1-10. DOI: 10.1016/00063207(92)91201-3.

Gause, G.F. (1931). The influence of ecological factors on the size of population. Am. Nat., 65, 70-76.

Gause, G.F. (1934). The struggle for existence. New York: MacMillan.

Gilbert, G.S. \& Webb C.O. (2007). Phylogenetic signal in plant pathogen-host range. Proc. Natl. Acad. Sci. USA, 104, 4979-4983. DOI: 10.1073/pnas.0607968104. 
Gotelli, N.J. (2000). Null model analysis of species co-occurrence patterns. Ecology, 81, 2606-2621. DOI: 10.1890/0012-9658(2000)081[2606:NMAOSC]2.0.CO;2.

Hardy, O.J. \& Senterre B. (2007). Characterizing the phylogenetic structure of communities by an additive partitioning of phylogenetic diversity. J. Ecol., 95, 493-506. DOI: 10.1111/j.1365-2745.2007.01222.x.

Hardy, O.J. (2008). Testing the spatial phylogenetic structure of local communities: statistical performances of different null models and test statistics on a locally neutral community. J. Ecol., 96, 914-926. DOI: 10.1111/j.13652745.2008.01421.x.

Havrda, M. \& Charvát F. (1967). Quantification method of classification processes: concept of structurala-entropy. Kybernetika, 3, 30-35.

Hertweck, K.L., Kinney, M.S., Stuart, S.A., Maurin, O., Mathews, S., Chase, M.W., Gandolfo, M.A. \& Pires J.Ch. (2015). Phylogenetics, divergence times and diversification from three genomic partitions in monocots. Bot. J. Linn. Soc., 178 (3), 375-393. DOI: 10.1111/boj.12260.

Hill, M.O. (1973). Reciprocal averaging: an eigenvector method of ordination. J. Ecol., 61, 237-249. DOI: $10.2307 / 2258931$.

Hubbell, S.P. (2001). The unified neutral theory of biodiversity and biogeography. New Jersey: Princeton University Press.

Izsáki, J. \& Papp L. (1995). Application of the quadratic entropy indices for diversity studies of drosophilid assemblages. Environ. Ecol. Stat., 2, 213-224. DOI: 10.1007/BF00456668.

Kosets, M.I. \& Tkachanko V.S. (1973). The vegetation of the sand. The vegetation of the URSR (in Ukrainian). Kyiv: Naukova Dumka.

Lamouroux, N., LeRoy Poff, N. \& Angermeier P.L. (2002). Intercontinental convergence of stream fish community traits along geomorphic and hydraulic gradients. Ecology, 83, 1792-1807. DOI: 10.1890/0012-9658(2002)083[1792:IC OSFC]2.0.CO;2.

Legendre, P. \& Gallagher E.D. (2001). Ecologically meaningful transformations for ordination of species. Oecologia, 129(2), 271-280. DOI: 10.1007/s004420100716.

Leibold, M. (1998). Similarity and local coexistence of species in regional biotas. Evol. Ecol., 12, 95-100. DOI: 10.1023/A:1006511124428.

Lord, J., Westoby, M. \& Leishman M. (1995). Seed size and phylogeny in 6 temperate floras - constraints, niche conservatism, and adaptation. Am. Nat., 146, 349-364. DOI: 10.1086/285804.

Losos, J.B. (1992). The evolution of convergent structure in Caribbean Anoliscommunities. Syst. Biol., 41, 403-420.

MacArthur, R. \& Levins R. (1967). The limiting similarity, convergence, and divergence of coexisting species. Am. Nat., 101, 377-385. DOI: 10.1086/282505.

Mouquet, N., Devictor, V., Meynard, C.N., Munoz, F., Bersier, L-F., Chave, J., Couteron, P., Dalecky, A., Fontaine, C., Gravel, D., Hardy, O.J., Jabot, F., Lavergne, S., Leibold, M., Mouillot, D., Münkemüller, T., Pavoine, S., Prinzing, A., Rodrigues, A.S.L., Rohr, R.P., Thébault, E. \& Thuiller W. (2012). Ecophylogenetics: advances and perspectives. Biol. Rev., 87, 769-785. DOI: 10.1111/j.1469-185X.2012.00224.x.

Pavoine, S., Dufour, A.-B. \& Chessel D. (2004). From dissimilarities among species to dissimilarities among communities: a double principal coordinate analysis. J. Theor. Biol., 228, 523-537. DOI: 10.1016/j.jtbi.2004.02.014.

Pavoine, S., Love, M.S. \& Bonsall M.B. (2009). Hierarchical partitioning of evolutionary and ecological patterns in the organization of phylogenetically-structured species assemblages: application to rockfish (genus: Sebastes) in the Southern California Bight. Ecol. Lett., 12, 898-908. DOI: 10.1111/j.1461-0248.2009.01344.x.

Potapenko, O.V. \& Zhukov O.V. (2016). Ecomorphic analysis of the plant cover of the electrical power substation (in Russian). Issues of Steppe Forestry and Forest Eclamation of Soils, 45, 138-147.

Qian, H., Hao, Z. \& Zhang J. (2014). Phylogenetic structure and phylogenetic diversity of angiosperm assemblages in forests along an elevational gradient in Changbaishan, China. Journal of Plant Ecology, 7, 154-165. DOI: $10.1093 /$ jpe/rtt072.

Qian, H. \& Jin Y. (2016). An updated megaphylogeny of plants, a tool for generating plant phylogenies and an analysis of phylogenetic community structure. Journal of Plant Ecology, 9(2), 233-239. DOI: 10.1093/jpe/rtv047.

R Core Team (2016). R: A language and environment for statistical computing. R Foundation for Statistical Computing, Vienna, Austria. URL https://www.R-project.org/.

Rao, C.R. (1982). Diversity and dissimilarity coefficients: A unified approach. Theor. Popul. Biol., 21, 24-43. DOI: 10.1016/0040-5809(82)90004-1.

Ricklefs, R.E. (1987). Community diversity: relative roles of local and regional processes. Science, 235, 167-71. DOI: $10.1126 /$ science.235.4785.167. 
Ricklefs, R.E. \& Schluter D. (1993). Species diversity: regional and historical influences. In R.E. Ricklefs \& D. Schluter (Eds.), Species diversity in ecological communities (pp. 350-363). Chicago: University of Chicago Press.

Shannon, C.E. (1948). A mathematical theory of communication. Bell System Technology Journal, 27, 379-423. DOI: 10.1002/j.1538-7305.1948.tb01338.x.

Simpson, E.H. (1949). Measurement of diversity. Nature, 163, 688. DOI: 10.1038/163688a0.

Sokolov, S.G. \& Zhukov A.V. (2016). The diversity of parasites in the Chinese sleeper Perccottus glenii Dybowski, 1877 (Actinopterygii: Perciformes) under the conditions of large-scale range expansion. Biology Bulletin, 43(4), 374-383. DOI: 10.1134/S1062359016040129.

The Plant List (2013). Version 1.1. Published on the Internet; http://www.theplantlist.org/ (accessed 1st January).

Tilman, D. (1982). Resource competition and community structure. Princeton: Princeton University Press.

Tofts, R. \& Silvertown J. (2000). A phylogenetic approach to community assembly from a local species pool. Proc. $R$. Soc. Lond. B, 267, 363-369. DOI: 10.1098/rspb.2000.1010.

Ulrich, W. (2004). Species co-occurrences and neutral models: reassessing J.M. Diamond's assembly rules. Oikos, 107, 603-609. DOI: 10.1111/j.0030-1299.2004.12981.x.

Voronov, A.G. (1973). Geobotany (in Russian). Moscow: Vischaya Shoal.

Warwick, R.M. \& Clarke K.R. (1995). New 'biodiversity' measures reveal a decrease in taxonomic distinctness with increasing stress. Mar. Ecol. Prog. Ser., 129, 301-305. DOI: 10.3354/meps129301.

Webb, C.O. (2000). Exploring the phylogenetic structure of ecological communities: an example for rain forest trees. Am. Nat., 156, 145-155. DOI: 10.1086/303378.

Webb, C.O., Ackerly, D.D., McPeek, M.A. \& Donoghue M.J. (2002) Phylogenies and community ecology. Annu. Rev. Ecol. Evol. Syst., 33, 475-505. https://doi.org/10.1146/annurev.ecolsys.33.010802.150448

Webb, C.O. \& Donoghue M.J. (2005). Phylomatic: tree assembly for applied phylogenetics. Mol. Ecol. Notes, 5(1), 181-183. DOI: 10.1111/j.1471-8286.2004.00829.x.

Weiher, E. \& Keddy P.A. (1995). The assembly of experimental wetland plant communities. Oikos, 73, 323-335. DOI: $10.2307 / 3545956$.

Weiher, E., Clarke, G.D.P. \& Keddy P.A. (1998). Community assembly rules, morphological dispersion, and the coexistence of plant species. Oikos, 81, 309-322. DOI: 10.2307/3547051.

Weiher, E. \& Keddy P.A. (1999). Ecological assembly rules: perspectives, advances, retreats. Cambridge: Cambridge University Press.

Wikström, N., Savolainen, V. \& Chase M. (2001). Evolution of the angiosperms: calibrating the family tree. Proc. R. Soc. Lond. B, 268, 2211-2220. DOI: 10.1098/rspb.2001.1782.

Zanne, A.E., Tank, D.C., Cornwell, W.K., Eastman, J.M., Smith S.A., FitzJohn, R.G., McGlinn D.J., O'Meara, B.C., Moles A.T., Reich, P.B., Royer D.L., Soltis, D.E., Stevens, P.F., Westoby M., Wright, I.J., Aarssen L., Bertin, R.I., Calaminus A., Govaerts, R., Hemmings F., Leishman M.R., Oleksyn, J., Soltis P.S., Swenson N.G. \& Warman L. (2014). Three keys to the radiation of angiosperms into freezing environments. Nature, 506, 89-92. DOI: 10.1038 /nature 12872

Zhukov, A.V. (2015a). Phytoindicator estimation of the multidimensional scaling of the plant community structure (in Russian). Biological Bulletin of Bogdan Chmelnitskiy Melitopol State Pedagogical University, 1(1), 69-93. DOI: 10.15421/2015005.

Zhukov, A.V. (2015b). Phytoindicator estimation of the multidimensional scaling dimension of the plant communities structure (in Ukrainian). Chornomorskij Botaničkij Žurnal, 11(1), 84-98. DOI: 10.14255/23089628/15.111/8

Zhukov, A.V., Kunah, O.N., Novikova, V.A. \& Ganzha D.S. (2016). Phytoindicacion estimation of catena communities of soil mesofauna and their ecomorphic organization (in Russian). Biological Bulletin of Bogdan Chmelnitskiy Melitopol State Pedagogical University, 6(3), 91-117. DOI: 10.15421/201676.

Zhukov, O.V. \& Potapenko O.V. (2017). Environmental impact assessment of distribution substations: the case of phytoindication (in Ukrainian). Ukrainian Journal of Ecology, 7(1), 5-21. DOI: 10.15421/20171. 